\title{
MICRONIZED CRUMB RUBBER INFLUENCE ON INDEX PROPERTIES OF WARM ASPHALT BINDERS
}

\author{
Ahmad Batari* ${ }^{1}$, Saeed Modibbo Saeed ${ }^{1}$, Mu'azu Balarabe Babangida ${ }^{2}$, \\ Isa Zubairu', Mohamad Yusri Aman ${ }^{3}$ \\ ${ }^{1}$ Department of Civil Engineering, Abubakar Tafawa Balewa University, PMB 0248, Bauchi, \\ Nigeria*Correspondence email/Phone number: ahmadbatari@gmail.com /+2348108471010 \\ ${ }^{2}$ Nigerian Institute of Leather and Science Technology (NILEST) Samaru, Zaria, Nigeria \\ ${ }^{3}$ Associate Professor, Faculty of Civil and Environment Engineering, University Tun Hussein \\ Onn Malaysia, 86400 Parit Raja. Batu Pahat, Johor, Malaysia
}

\begin{abstract}
Primarily, the main aim of recycling waste tires in the form of micronized crumb rubber into asphalt cement as modifiers are to enhance their engineering properties in addition to the associated solid waste management benefits. Often, these modifiers are used to achieve reasonably stiffer binders i.e.; low penetration; high softening point; and high penetration index, to realize higher resistance to deformation under the influence of traffic and temperature. The study assessed the effects of Micronized Crumb Rubber (MCR) on the penetration, softening point, and penetration index of 80-100 PEN bitumen impregnated with $2.5 \%$ Sasobit (fixed by weight). The MCR modified warm asphalt binders were prepared by further blending with different percentages of minus 40 mesh size MCR powder (from0 - 15 $\%$ by weight of the bitumen stepped at 2.5\%). Subsequently, penetration and softening point tests were conducted on each blend, and the corresponding penetration indices were evaluated. The results show that MCR addition gradually decreases the penetration values while conversely increases both the softening point values and the penetration indices as well. Thus, MCR might be used to improve the flow and thermal susceptibility resistance of warm asphalt binders.
\end{abstract}

Keywords: Bitumen, micronized crumb rubber, penetration, softening point, penetration index 


\subsection{Introduction}

Asphalt binder properties are among the key defining features of asphalt mixtures, even those binders with similar physical properties such as viscosity, penetration, softening point and grade, can exhibit different rheological properties (Abed \& Al-haddad, 2020). However, the most common conventional way of characterizing asphalt binders (or bitumen) is still with the needle penetration test despite the advantages of the performance grading, penetration as an index property measures the viscous resistance to penetration of the needle into bitumen sample (Khairuddin, Nazrul, Ibrahim, Rahmad, \& Yusoff, 2018).

Various groups of bitumen modifiers (such as; chemicals, polymers, natural rubbers, crumb rubber, etc) have been used to enhance certain properties of binders in asphalt production (Abed \& Al-haddad, 2020); (Mirzaiyan, Ameri, Amini, Sabouri, \& Norouzi, 2019). This is because; unmodified bitumen may have the following weaknesses:

i. Flow under high temperature leading to permanent deformation (rutting).

ii. Fracture at low temperature leading to pavement cracking.

iii. Bond breaking as the bitumen to aggregate adhesion may break down under a combination of aging and water attack.

Crushed waste rubber tires often referred to as 'Crumb Rubber' (CR) can be added to bitumen to improve their resistance to damage, to improve the service life of bituminous pavements( $\mathrm{Li}$ et al., 2016), in the event the rubber crumb has been grounded and screened to finer than $425 \mu m$ (40 US mesh size) then it is termed Micronized Crumb Rubber (MCR).In recent years, much of the pressure for the use of MCR has come from the need to find ways of recycling used vehicle tyres. MCR powder can reduce the thermal sensitivity of bituminous binders, but because MCR-modified binders require higher temperatures to produce, warm asphalt additives such as sasobit can be added to lessen the production temperature (Batari, Aman, Saeed, Ahmed, \& Chinade, 2017). Conventionally,the thermal susceptibility of binders is expressed quantitatively using Penetration Index $(P)$, thus, PI measures the response of asphalt binders to temperature variation, besides, binder type pertaining thermal (temperature) susceptibility can be easily identified using its PI value(Iqbal, Hussain, Khattak, \& Ahmad, 2020). The addition of MCR enhanced the penetration index (PI) of the binders thus reducing their temperature sensitivity(Ariyapijati, Hadiwardoyo, \& Sumabrata, 2019).The studyassessed the effects of MCR on penetration, softening point, and penetration indices of warm asphalt binders.

\subsection{Materials and Methods}

The material used in this study are; 80/100 penetration grade bitumen; sasobit (fixed at 2.5 $\%$ ); and Micronized Crumb Rubber (MCR).The MCR was produced by mechanical shredding of the waste rubber tires followed by grinding at ambient temperature,thereafter, the crumb is sieved through a 425 -micron sieve. The methodology employed is simply outlined in Figure 1. 


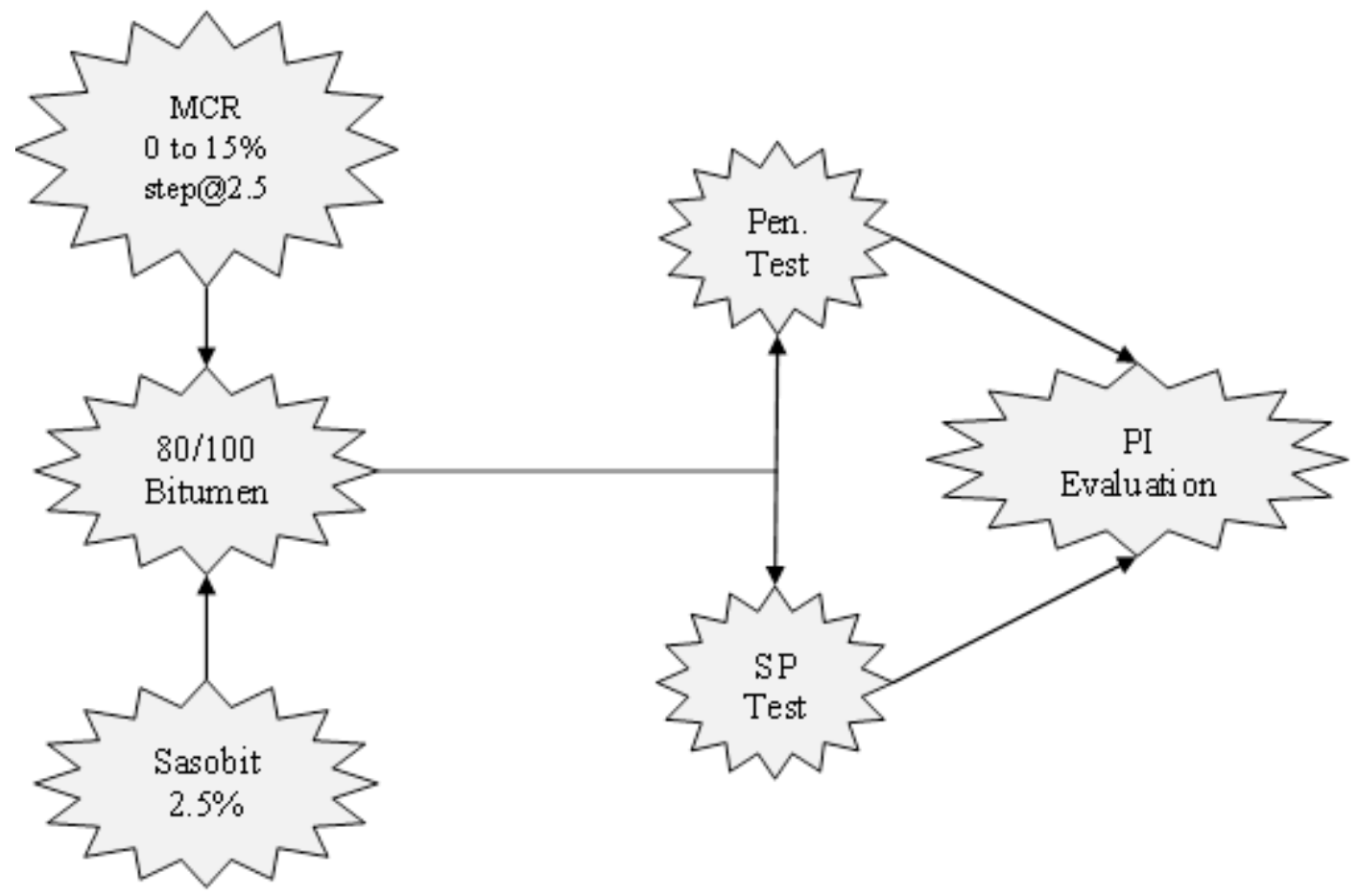

Figure 1: Methodology Outline

\subsection{Binder Preparation}

The MCR modified binders were prepared by mixing the original 80 - 100 penetration grade bitumen with Sasobit by a wet process. $0 \%, 2.5 \%, 5 \%, 7.5 \%, 10 \%, 12.5 \%$, and $15 \%$ MCR by weight of the base binder was added to produce the micronized crumb rubber modified warm asphalt binders. MCR blending was conducted at $177^{\circ} \mathrm{C}$ agitating continuously for $30 \mathrm{~min}$, using a high shear mixerrotating at 700rpm (Batari et al., 2017). Then, 2.5\% Sasobit by weight of the base binder which is within the recommended dosage of 0.8 to $3 \%$ was then mixed at $120^{\circ} \mathrm{C}$, while, the shearing rate and time used was $1000 \mathrm{rpm}$ and 10 minutes respectively. The prepared MCR modified warm asphalt binders were used instantaneously, due to their poor storage stability (Liang et al., 2015) to avoid setting apart.

\subsection{Penetration Test}

The penetration value of a bituminous material is a measure of its consistency expressed as the distance in a tenth of a millimeter that a standard needle penetrates vertically into a sample of material under known conditions of loading time and temperature.This test was conducted based on AASHTO T49-03 (AASHTO, 2004), the prepared samples for the test were placed at the prescribed temperature for one hour before the test commences. The 100 grams needle was placed at $90^{\circ}$ just at the surface of the specimen. The needle was then allowed to penetrate the binder specimen freely, under its weight for 5 seconds; the test temperature was maintained at $25^{\circ} \mathrm{C}$. 


\subsection{Softening Point Test}

The softening point test was conducted using Ring and Ball apparatus following AASHTO T53-96 (AASHTO, 2004), the purpose was to determine the temperature at which a bitumen or binder sample can no longer support the weight of a $3.5 \mathrm{~g}$ steel ball. Two horizontal disks of bitumen, cast in shouldered brass rings, were heated at a controlled rate in a water bath while each supports a steel ball (The whole setup was conditioned at a temperature of $25^{\circ} \mathrm{C}$ for 15 minutes in water to a depth of $105 \mathrm{~mm}$ before the balls were placed on the rings. thereafter, it was transferred quickly onto a hot plate where it was heated at a constant rate of $5^{0} \mathrm{C}$ per minute). The softening points were reported as the mean of the temperatures at which the two disks soften enough to allow each ball, enveloped in bitumen, to fall a distance of 25 $\mathrm{mm}$.

\subsection{Penetration Index (PI)Evaluation}

The penetration index (PI) refers to the quantitative indicator that measures asphalt binder susceptibility or responses to change in temperature. The value of PI ranges from around -3 for high-temperature susceptible bitumens to around +7 for extremely low-temperature susceptible asphalt binders(Abed \& Al-haddad, 2020) (Ehinola, Falode, \& Jonathan, 2012). While normal asphalt binders(i.e. paving grade) have PI ranging between -2 and +2 (Iqbal et al., 2020). Thus, Increasing PI values to more than +2 means that asphalt cement binders have low thermal susceptibility, while PI values less than -2 mean the binders are excessively susceptible to high temperature(Abed \& Al-haddad, 2020). The PI as thermal susceptibility indicator is a dimensionless parameter whose values were computed based on the results obtained from softening point and penetration tests using Eq. (1) as presented (Robert, Self, \& Read, 2015).

$P I$

$=\frac{1952-500 * \log _{10}\left(P e n_{@ 25}\right)-20 * S P}{50 * \log _{10}\left(P e n_{@ 25}\right)-S P-120}$

Where; $P e n_{@ 25}$ is the penetration value measured at $25{ }^{\circ} \mathrm{Cin} 0.1 \mathrm{~mm}$ and $\mathrm{SP}$ is the softening point of the binder in ${ }^{0} \mathrm{C}$.

\subsection{Penetration Test Results}

This test provides a means of measuring the consistency or hardness of bituminous material, in a penetration grading system these penetration values are used to classify the material into grades, the lower the value the stiffer the binder (AASHTO, 2004) thus the higher the thermal susceptibility resistance, however, the use of stiffer but workable binder is vital. The virgin binder has an average penetration value of $88 \mathrm{dmm}$. The penetration values for warm asphalt binder with $0 \%$ MCR is $68 \mathrm{dmm}$, with $2.5 \%$ is $64 \mathrm{dmm}$, with $5 \%$ MCR is $59 \mathrm{~mm}$, with $7.5 \%$ is $54 \mathrm{dmm}$, with $10 \% \mathrm{MCR}$ is $49 \mathrm{dmm}$, and with $12.5 \%$ is $47 \mathrm{dmm}$ while that of warm asphalt binders with $15 \%$ MCR is $42 \mathrm{~mm}$ as shown inFigure 2. The penetration values (Pen) gradually decreases as the additive content increases, Brown et. al., (2009) attributed the decrease in penetration values to an increase in the viscosity and stiffness. For the virgin binder, it was observed that modification with $2.5 \%$ Sasobit and with the further addition of MCR, there was a gradual decrease in penetration values, to the extent that any further 
addition changes the binder grade by one step, except for $12.5 \%$ and $15 \%$ MCR addition, even though they are stiffer, but have the same penetration grade as a blend with $10 \% \mathrm{MCR}$. Therefore, micronized crumb rubber (MCR) addition to warm asphalt binders (incorporating $2.5 \%$ sasobit) reduces their penetration value. From regression analysis; it was established that a strong relationship seems to exist between Pen and MCR,and is best fitted with quadratic function presented in Eq. (2) with $99.5 \%$ R-square value.

$$
\text { Pen }=68.38-2.029 * M C R+0.01905 * M C R^{2}
$$

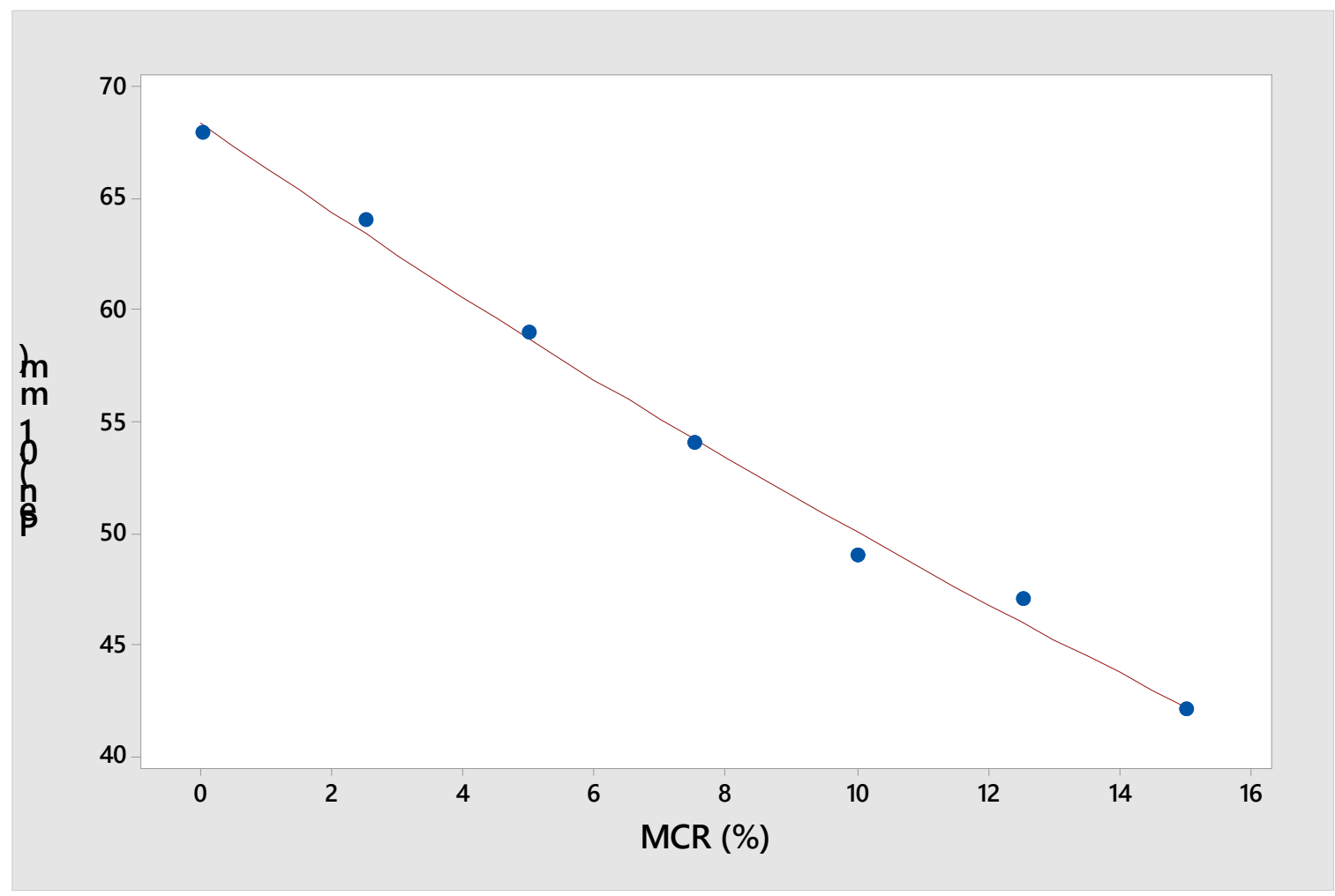

Figure 2: Effect of MCR on Penetration of Warm Asphalt Binders

\subsection{Softening Point Test Results}

Asphalt binders do not have sharp defined melting points due to their viscoelastic nature; they gradually become softer with increasing temperature. Therefore Softening point serves as an indicator of the tendency of bituminous material to flow at higher working temperatures (AASTO, 2004). This test was conducted per AASHTO T53-96, the softening point of the original binder was $45^{\circ} \mathrm{C}$. while for the warm asphalt binders are; $54^{0} \mathrm{C}, 56{ }^{0} \mathrm{C}, 57^{0} \mathrm{C}$, $58^{\circ} \mathrm{C}, 60^{\circ} \mathrm{C}, 62{ }^{\circ} \mathrm{C}$, and $64^{\circ} \mathrm{C}$ at $0 \%, 2.5 \%, 5 \%, 7.5 \%, 10 \%, 12.5 \%$, or $15 \%$ MCR addition respectively as presented in Figure 3. Furthermore, the addition of $2.5 \%$ sasobit to the original binder ( $0 \%$ MCR) increases its softening point (SP) by $18 \%$. On the other hand, binderblends with $15 \%$ MCR have the maximum corresponding increases in softening point value by $40 \%$. There was a general gradual increase in softening point values with additive incorporation. For the statistical analysis of variance (ANOVA), MCR (\%) was set as the influencing variable while the softening point was set as the response variable. From the ANOVA result, MCR hasa significant effect on the softening point, with a p-value of 0.0027 , 
less than the assumed $\alpha$ of 0.05 at $95 \%$ confidence level.Also, the $\mathrm{R}^{2}$ value from the regression model was $99.5 \%$,which signifiesa strongcorrelation.

$$
S P=54.14+0.6651 * M C R^{2}-0.02667 * M C R^{3}
$$

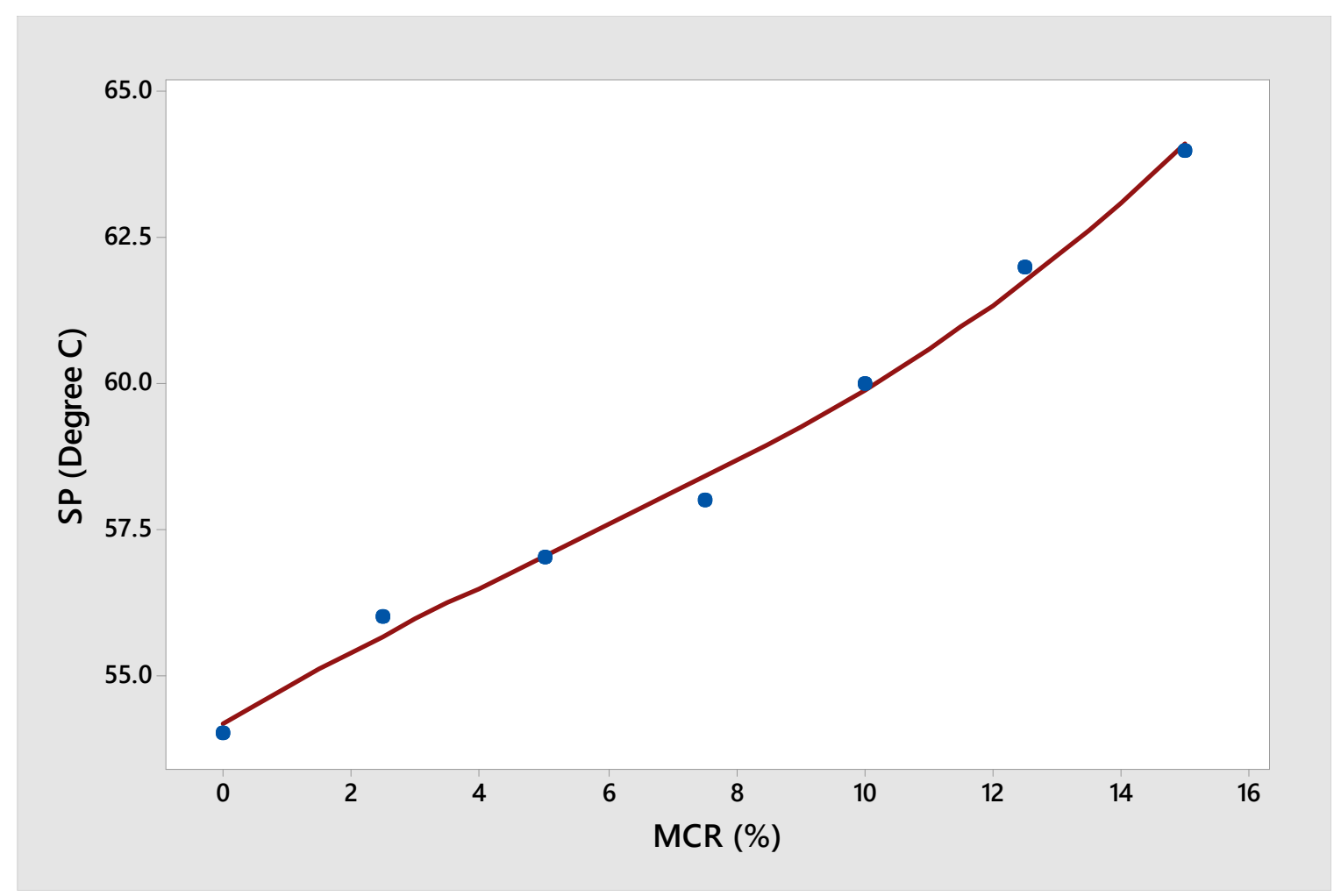

Figure 3: Effect of MCR on Softening Point of Asphalt Binders

\subsection{Penetration Index Results}

The results of penetration index (PI) which is a surrogate measure of thermal susceptibility of asphalt binders is presented in Figure 4, the PI value of the warm asphalt binders with $2.5 \%$ sasobit with $0 \%$ MCR increased to +0.120134 as against the PI value of the original unmodified asphalt $(-0.172348)$ binder. The highest improvement in PI value $(+0.457079)$ of the warm asphalt binders was achieved at $15 \%$ MCR addition. An overall gradual increase in PI values with increasing MCR content was observed. Moreover, the PI values of the entire binders are within the acceptable limit (Radovskiy \& Teltayev, 2018). 


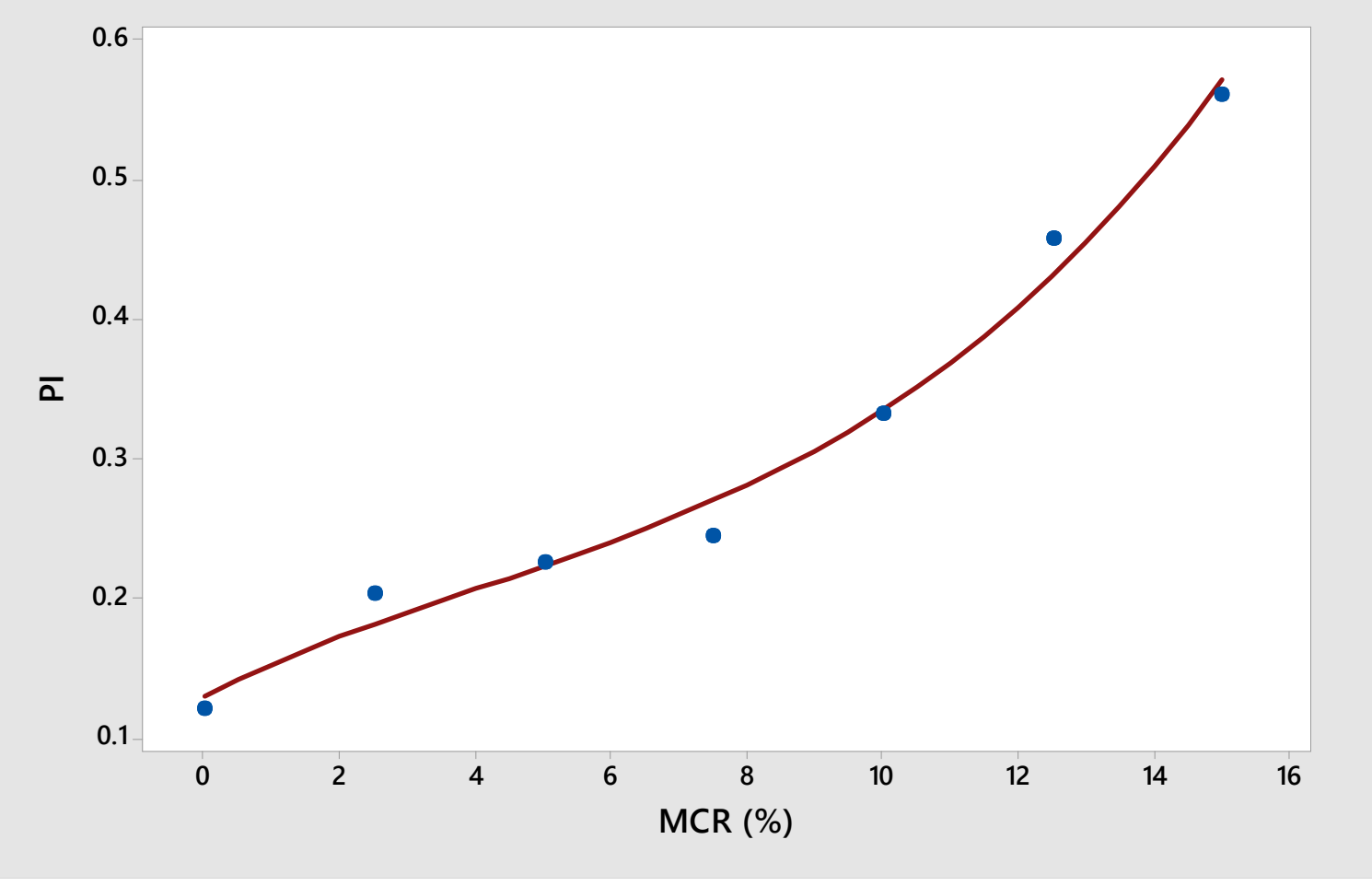

Figure 4: Effect of MCR on Penetration Index of Warm Asphalt Binders

In the statistical analysis to establish the functional relationship among the variables (PI, Pen, $\mathrm{SP}$, and MCR); all the data sets were evaluated to be normally distributed with no outliers. However, in the regression (step-wise) model, MCR was eliminated due to multi-collinearity, therefore, it cannot be used alongside Pen, SP in a single model to predict PI. The model in Eq. (4) has a correlation coefficient of $99.79 \%$, and an adjusted determination coefficient of $99.68 \%$, this suggestsa higher correlation among the model parameters. Also, from the analysis of variance presented in Table 1, the influence variables penetration value (Pen) and softening point values (SP) have $p$-values less than 0.05 at $95 \%$ confidence level, this suggest they have statistical significance in predicting penetration index (PI) of the MCR modified warm asphalt binders.

$$
\begin{aligned}
P I=-4.788 & +0.01199 * \text { Pen }+0.07558 \\
& * S P
\end{aligned}
$$

Table 1: Analysis of Variance

\begin{tabular}{lrrrrr}
\hline Source & DF & Adj SS & Adj MS & F-Value & P-Value \\
\hline Regression & 2 & 0.143723 & 0.071861 & 935.37 & 0.000 \\
Pen & 1 & 0.002856 & 0.002856 & 37.17 & 0.004 \\
SP & 1 & 0.015552 & 0.015552 & 202.43 & 0.000 \\
Error & 4 & 0.000307 & 0.000077 & & \\
Total & 6 & 0.144030 & & & \\
Coefficients & & & & & \\
\hline Term & Coef & SE Coef & T-Value & P-Value & VIF \\
\hline Constant & -4.788 & 0.418 & -11.45 & 0.000 & \\
Pen & 0.01199 & 0.00197 & 6.10 & 0.004 & 26.97 \\
SP & 0.07558 & 0.00531 & 14.23 & 0.000 & 26.97 \\
\hline
\end{tabular}




\subsection{Conclusions}

The results of an analysis of the experimental data for the unmodified and warm asphalt blends modified with varying quantities of micronized crumb rubber (MCR) have shown that; Sasobit reduces the penetration (Pen) values of warm asphalt binders while on the other hand increases both softening point (SP) and penetration index (PI) compared to the original $80 / 100$ pen grade bitumen. Similarly, the addition of MCR reduces the penetration and increases the softening points and penetration indices of the warm asphalt binders. 


\section{References}

1. AASHTO (2004). 'Standard Specifications for Transportation Materials and Methods of Sampling and Testing', 24th Edition. Washington, D.C.

2. Abed, Y. H., \& Al-haddad, A. H. A. (2020). Temperature Susceptibility of Modified Asphalt Binders. IOP Conference Series: Materials Science and Engineering, 671(012121). https://doi.org/10.1088/1757-899X/671/1/012121

3. Ariyapijati, R. H., Hadiwardoyo, S. P., \& Sumabrata, R. J. (2019). Developing Resilient Modulus Model for Modified Asphalt Mixes with Crumb Rubber and Buton Natural Asphalt Based on Penetration Index and Temperature. International Journal of Engineering Research and Technology, 12(12), 2709-2714.

4. Batari, A., Aman, M. Y., Saeed, S. M., Ahmed, T. Y., \& Chinade, A. U. (2017). Rutting Assessment of Crumb Rubber Modifier Modified Warm Mix Asphalt Incorporating Warm Asphalt Additive. International Research Journal of Engineering and Technology (IRJET), 04(02), 1239-1244.

5. Brown, E. R., Kandhal, P. S., Roberts, F. L., Kim, Y. R., Lee, D. Y., \& Kennedy, T. W. (2009). Hot mix asphalt materials, mixture design and construction (Third). Maryland: NAPA Research and Education Foundation, Lanham.

6. Ehinola, O. A., Falode, O. A., \& Jonathan, G. (2012). Softening point and Penetration Index of bitumen from parts of Southwestern Nigeria. NAFTA, 63(9-10), 319-323.

7. Iqbal, M., Hussain, A., Khattak, A., \& Ahmad, K. (2020). Improving the Aging Resistance of Asphalt by Addition of Polyethylene and Sulphur. Civil Engineering Journal, 6(5), 1017-1030.

8. Khairuddin, F. H., Nazrul, A., Ibrahim, H., Rahmad, S., \& Yusoff, N. I. (2018). Aging Effect on the Physical Properties of Polyurethane Modified Bitumen. 7, 410-413.

9. Li, S., Huang, Y., \& Liu, Z. (2016). Experimental evaluation of asphalt material for interlayer in rigid-flexible composite pavement. Construction and Building Materials, 102, 699-705. https://doi.org/10.1016/j.conbuildmat.2015.10.122

10. Liang, M., Xin, X., Fan, W., Luo, H., Wang, X., \& Xing, B. (2015). Investigation of the rheological properties and storage stability of CR / SBS modified asphalt. Construction and Building Materials, 74, 235-240. https://doi.org/10.1016/j.conbuildmat.2014.10.022

11. Mirzaiyan, D., Ameri, M., Amini, A., Sabouri, M., \& Norouzi, A. (2019). Evaluation of the performance and temperature susceptibility of gilsonite- and SBS-modified asphalt binders. Construction and Building Materials, 207, 679-692. https://doi.org/10.1016/j.conbuildmat.2019.02.145

12. Radovskiy, B., \& Teltayev, B. (2018). Viscoelastic Properties of Asphalts Based on Penetration and Softening Point (A. F. O. C. Jose \& M. P. D. J. Abilio, eds.). Springer International Publishing AG, Switzerland. https://doi.org/10.1007/978-3-319-67214-4

13. Robert, N. H., Self, A., \& Read, J. (2015). The Shell Bitumen Handbook (Sixth Edit). Shell Bitumen by ICE Publishing, London. 